\title{
Congenital heart disease, prenatal diagnosis and management
}

\author{
César H. Meller M.D. ${ }^{a}$, Sofía Grinenco M.D. ${ }^{b}$, Horacio Aiello M.D. ${ }^{a}$, Antonela Córdoba M.D. ${ }^{b}$, \\ María M. Sáenz-Tejeira M.D. ${ }^{b}$, Pablo Marantz M.D. ${ }^{b}$ and Lucas Otaño M.D. ${ }^{a}$
}

\begin{abstract}
Among congenital malformations, heart defects are the most common type of anomaly, and these are associated with a high perinatal, longterm morbidity and mortality. The objective of this update was to review the rate of prenatal detection, screening characteristicsthroughoutthe pregnancy, in both the first and second trimesters, indications for advanced echocardiography, and to establish a management algorithm in case of prenatal diagnosis of a congenital heart disease. Potential invasive and non-invasive tests and obstetric follow-up will be discussed here. Finally, the main characteristics of fetal therapy in heart anomalies will be reviewed, both cardiac interventions and intrauterine treatment of arrhythmias.

Key words: congenital heart disease, prenatal diagnosis, fetal therapy, screening.

http: / / dx.doi.org/10.5546/ aap.2020.eng.e149

To cite: Meller CH, Grinenco S, Aiello H, Córdoba A, et al. Congenital heart disease, prenatal diagnosis and management. Arch Argent Pediatr 2020;118(2):e149-e161.
\end{abstract}

\section{INTRODUCTION}

Heart conditions, which are the most common type of congenital malformations, occur in $1 \%$ of newborn infants and are associated with a high perinatal morbidity and mortality. ${ }^{1}$ Prenatal diagnosis allows to provide the family guidance on prognosis, plan an adequate obstetric follow-up, offer intrauterine management for uncommon, especially selected cases, and, in case of a complex congenital heart disease (CHD), refer the pregnant woman to a tertiary care facility capable of providing neonatal diagnosis and management (through therapeutic catheterization and/or cardiovascular surgery), which has shown to reduce associated perinatal morbidity and mortality. ${ }^{1-3}$

\section{Rate of prenatal detection}

The rate of detection of CHD, even in developed countries, ranges between $30 \%$ and $60 \% .^{2,4-5}$ An analysis of data provided by Belgium to the European Registration of Congenital Anomalies and Twins (EUROCAT) reported that the rate of prenatal detection in the 1997-2012 period was $29.3 \%$ for all CHD in general and $40.2 \%$ for severe CHD. ${ }^{4}$ The Netherlands has a national quality control program and the rate of prenatal detection there for all $\mathrm{CHD}$ was $59.7 \%{ }^{2}$ In addition, a recent systematic review, ${ }^{5}$ which included 7 studies and 4992 patients, reported a $45.1 \%$ prenatal detection rate for CHD (95\% confidence interval [CI]: 33.5-57.0).

Besides the low prenatal diagnosis rate for CHD, another important aspect is its late detection. In Belgium, only $14.1 \%$ of CHD in general and $20.5 \%$ of severe CHD were diagnosed before 25 weeks of gestation. ${ }^{4}$ In Argentina, our group reported a series of 303 fetuses diagnosed prenatally, mostly referred from other facilities, where the mean gestational age at the time of diagnosis was $29.9 \pm 5$ weeks. ${ }^{6}$

Intrauterine detection depends on several factors, so it is critical for patients to have an easy access to the health system. Although in Argentina and in all Latin American countries this is highly relevant, it is not the only aspect to be taken into account because, as detailed above, even in countries with a high health care coverage, the overall detection of CHD does not exceed $50-60 \%$.

A second factor is sonographers' expertise in the assessment of the fetal heart. A high proportion of $\mathrm{CHD}$ without prenatal diagnosis is seen in patients who underwent several 
ultrasounds that only report the fetal heart rate without assessing the fetal heart anatomy. Therefore, it is critical to develop systematic training and ongoing quality programs, ${ }^{2-5}$ which are lacking in our setting.

Thirdly, even with trained operators, the test may be complex in patients with specific characteristics, such as maternal obesity or pregnancy with marked polyhydramnios (excessive amniotic fluid). ${ }^{1}$

Lastly, some pathologies are easily diagnosed, while others are rarely detected (Table 1). Thus, the rate of prenatal detection of hypoplastic left heart syndrome is high and may reach up to approximately $90 \%$ of cases ${ }^{2-5}$ whereas other CHD, such as anomalous venous return, are hardly detected in the prenatal period. ${ }^{1,2}$

\section{When and how to assess the fetal heart}

The fetal heart is assessed by means of a routine, detailed fetal ultrasound around week 20-24. At present, this test has been standardized by the International Society of Ultrasound in Obstetrics and Gynecology (ISUOG) and consists in a screening procedure including the fourchamber view (Figure 1), ventricular outflow tract view (Figure 2), and three-vessel and three-vessel and trachea views (Figure 3). ${ }^{7}$

In addition, a fetal echocardiogram is indicated in patients at a higher risk for CHD compared to the general population (Table 2). Among maternal indications, one of the most prevalent conditions is diabetes mellitus, which entails a risk 2-3 times higher for malformations than the general population. Such increased risk is related to glycosylated hemoglobin values: a higher glycosylated hemoglobin level leads to a higher risk for congenital defects. In relation to CHD, there is a higher risk for structural malformation due to an altered embryogenesis, potentially evident in early tests, ${ }^{8}$ and for septal hypertrophy and hypertrophic cardiomyopathy due to hyperinsulinism, which can be evidenced in the third trimester. ${ }^{9}$

Other maternal conditions that increase the risk for heart disease include autoimmune diseases with positive anti-Ro and anti-La antibodies, such as Sjögren syndrome and systemic lupus erythematosus. The risk for a complete atrioventricular block is $1-2 \%$ and, if a prior child has been affected, such risk increases to $15-20 \% .^{10}$

TABLE 1. Rates of detection by type of congenital heart disease and whether they are isolated or associated with other defect (non-isolated)

\begin{tabular}{|c|c|}
\hline Type of heart disease & $\begin{array}{c}\text { Rate of prenatal detection } \\
\%(95 \% \mathrm{CI})\end{array}$ \\
\hline $\begin{array}{l}\text { Single ventricle heart defect (isolated) } \\
\text { Hypoplasia of the left ventricle } \\
\text { Hypoplasia of the right ventricle } \\
\text { Ebstein's anomaly (isolated and non-isolated) } \\
\text { Truncus arteriosus (isolated and non-isolated) } \\
\text { AV canal (isolated and non-isolated) }\end{array}$ & $\begin{array}{c}\approx 60-95 \\
90.7(82.1-96.9) \\
63.7(45.1-80.1) \\
80.1(45.6-99.9) \\
69.1(43.1-90.6) \\
60.4(47.0-73.0)\end{array}$ \\
\hline $\begin{array}{l}\text { Tetralogy of Fallot } \\
\text { Isolated } \\
\text { Isolated and non-isolated }\end{array}$ & $\begin{array}{l}49.2(37.1-61.3) \\
42.0(30.9-53.6)\end{array}$ \\
\hline $\begin{array}{l}\text { Transposition of the great arteries } \\
\text { Isolated } \\
\text { Isolated and non-isolated }\end{array}$ & $\begin{array}{l}48.5(24.2-73.1) \\
36.4(21.0-53.3)\end{array}$ \\
\hline $\begin{array}{l}\text { Pulmonary atresia with VSD } \\
\text { Isolated } \\
\text { Isolated and non-isolated }\end{array}$ & $\begin{array}{l}37.8(27.2-49.1) \\
59.8(45.6-73.2)\end{array}$ \\
\hline $\begin{array}{l}\text { Pulmonary atresia with intact septum } \\
\text { Isolated and non-isolated }\end{array}$ & $41.3(25.5-57.9)$ \\
\hline $\begin{array}{l}\text { Coarctation of the aorta } \\
\text { Isolated } \\
\text { Isolated and non-isolated }\end{array}$ & $\begin{array}{l}30.6(19.1-43.5) \\
22.3(18.0-27.0)\end{array}$ \\
\hline $\begin{array}{l}\text { Anomalous venous return } \\
\text { Complex heterotaxy syndrome }\end{array}$ & $\begin{aligned} & \approx 10 \\
& \approx 80-90\end{aligned}$ \\
\hline
\end{tabular}

CI: confidence interval; VSD: ventricular septal defect; AV canal: atrioventricular canal (adapted from Van Velzen et al.). ${ }^{5}$ 
In terms of infections, varicella ${ }^{11}$ and rubella ${ }^{12}$ may lead to structural heart defects, whereas parvovirus is associated with heart failure secondary to severe anemia and myocarditis. ${ }^{13,14}$

CHD may also be the result of embryonic exposure to a wide range of chemicals. ${ }^{15} \mathrm{In}$ relation to recreational drugs, alcohol is the most prevalent agent. Among commonly used drugs in medicine, lithium, isotretinoin, misoprostol, and some anticonvulsant agents, such as phenobarbital and valproic acid, are associated with CHD. ${ }^{16}$
A positive family history is also a known risk factor for CHD. ${ }^{15}$ The risk of recurrence after having an affected child is 2-5\%, but varies broadly depending on the type of heart disease and increases even more in the case of more than one affected child. The risks are also higher when one of the parents has CHD, and the risk of recurrence is higher if the mother is the carrier (10-15\%) compared to the father $(2 \%){ }^{15}$

A fetal echocardiogram may also be indicated due to fetal findings during pregnancy control. Monozygotic twin pregnancies are at a higher

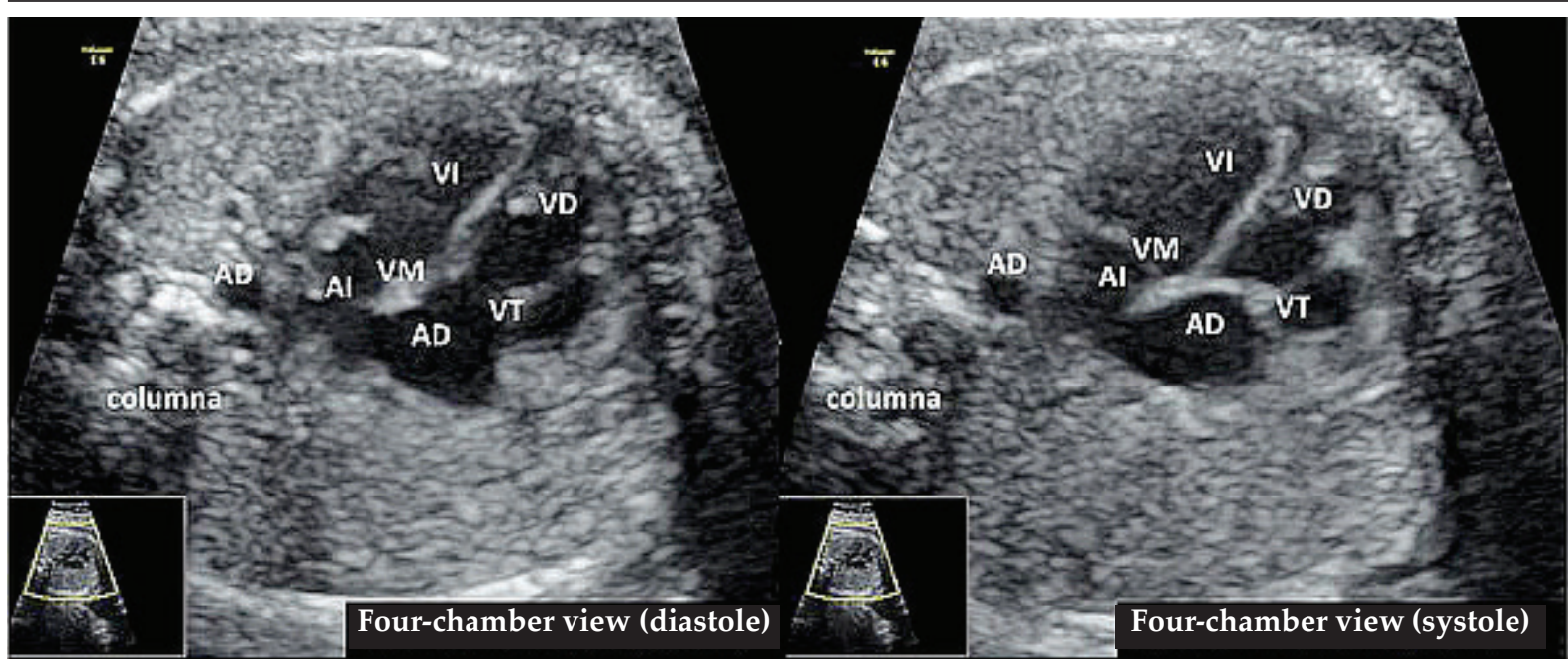

VI: left ventricle, VD: right ventricle, VM: mitral valve, VT: tricuspid valve, AI: left atrium, AD: right atrium, AO: descending aorta; columna: spine.

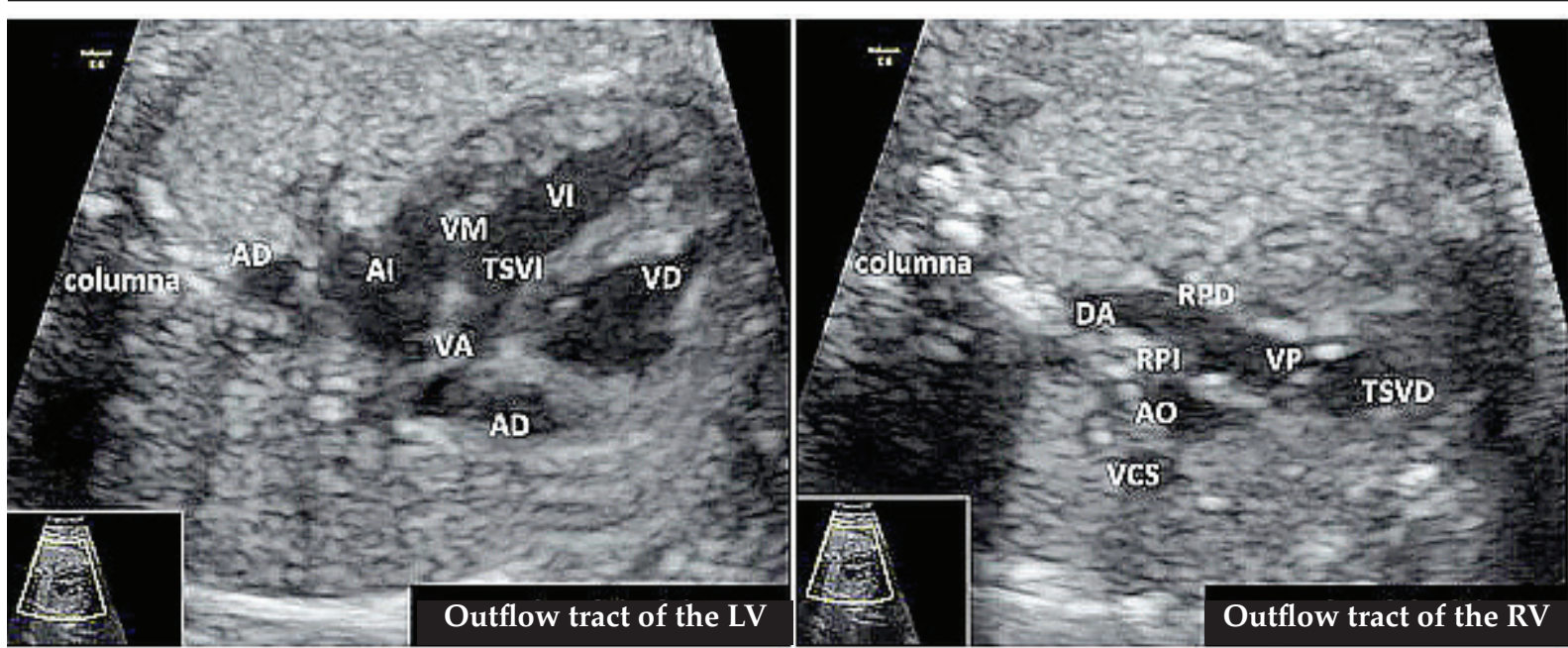

TSVI: left ventricular outflow tract; VI: left ventricle; TSVD: right ventricular outflow tract; VD: right ventricle; VM: mitral valve; VA: aortic valve; AI: left atrium, AD: right atrium, AO: aorta; VCS: superior vena cava; RPD: right pulmonary artery branch; RPI: left pulmonary artery branch; DA: ductus arteriosus; columna: spine. 
risk for congenital defects than the general population. In particular, in the twin-to-twin transfusion syndrome, the recipient twin has a $10 \%$ chance of having right ventricular outflow tract anomalies. ${ }^{17}$

Some ultrasound markers in the first trimester, such as nuchal translucency (NT) thickness, and ductus venosus (DV) and tricuspid valve Doppler ultrasound, used to screen for chromosomal anomalies, have also demonstrated their usefulness as CHD markers. On its side, at present, the assessment of the fetal anatomy during the second trimester has been standardized to cover both the fetal heart and the fetal anatomy, 7,18 and any finding from such baseline screening is a formal indication for a fetal echocardiogram. This test has also been recommended in case of prenatal diagnosis of chromosomal anomalies and microdeletion syndromes, ${ }^{15}$ especially in viable anomalies such as trisomy 21, which is strongly associated with the atrioventricular canal, monosomy of the $\mathrm{X}$ chromosome, associated with coarctation of the aorta, and microdeletion 22q11.2 or DiGeorge syndrome, associated with conotruncal anomalies. Likewise, the molecular diagnosis of a Mendelian pathology is an indication for a heart assessment by a specialist.
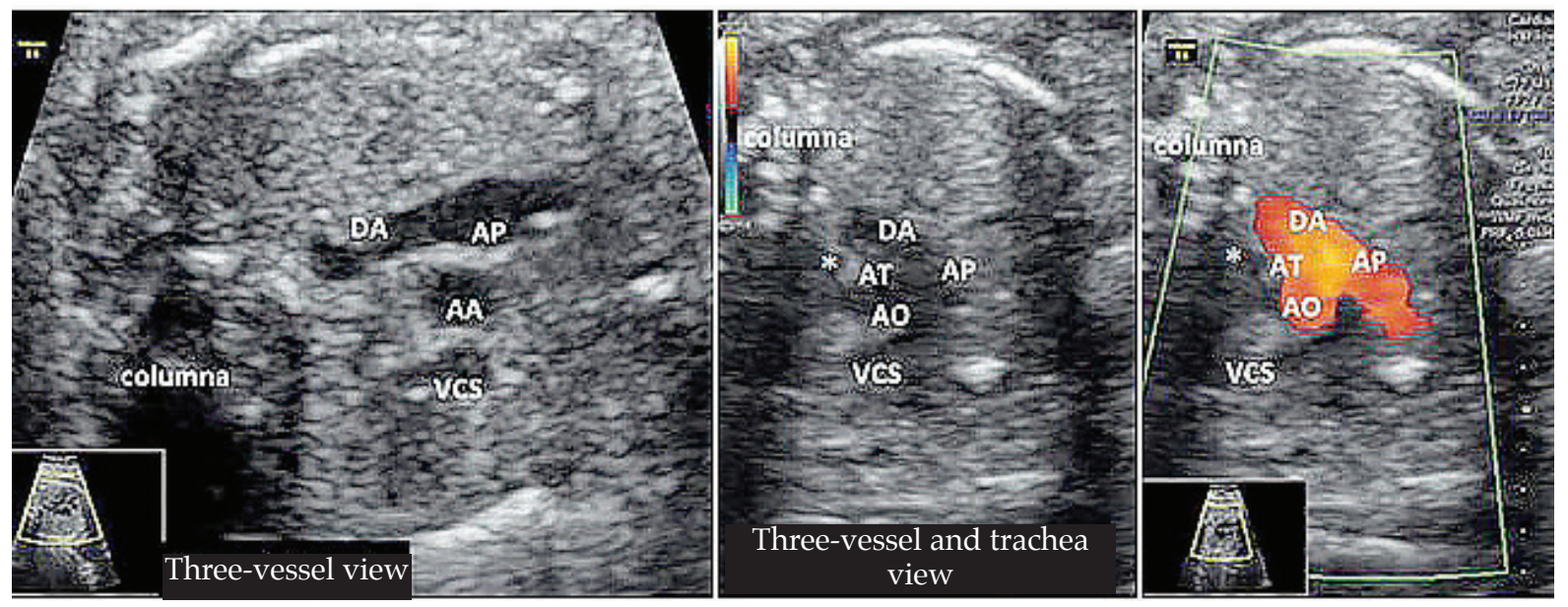

AA: ascending aorta; AP: pulmonary artery; AO: aorta; VCS: superior vena cava; DA: ductus arteriosus;

AT: transverse aortic arch; * trachea; columna: spine.

TABLE 2. Indications for fetal echocardiogram based on risk factors

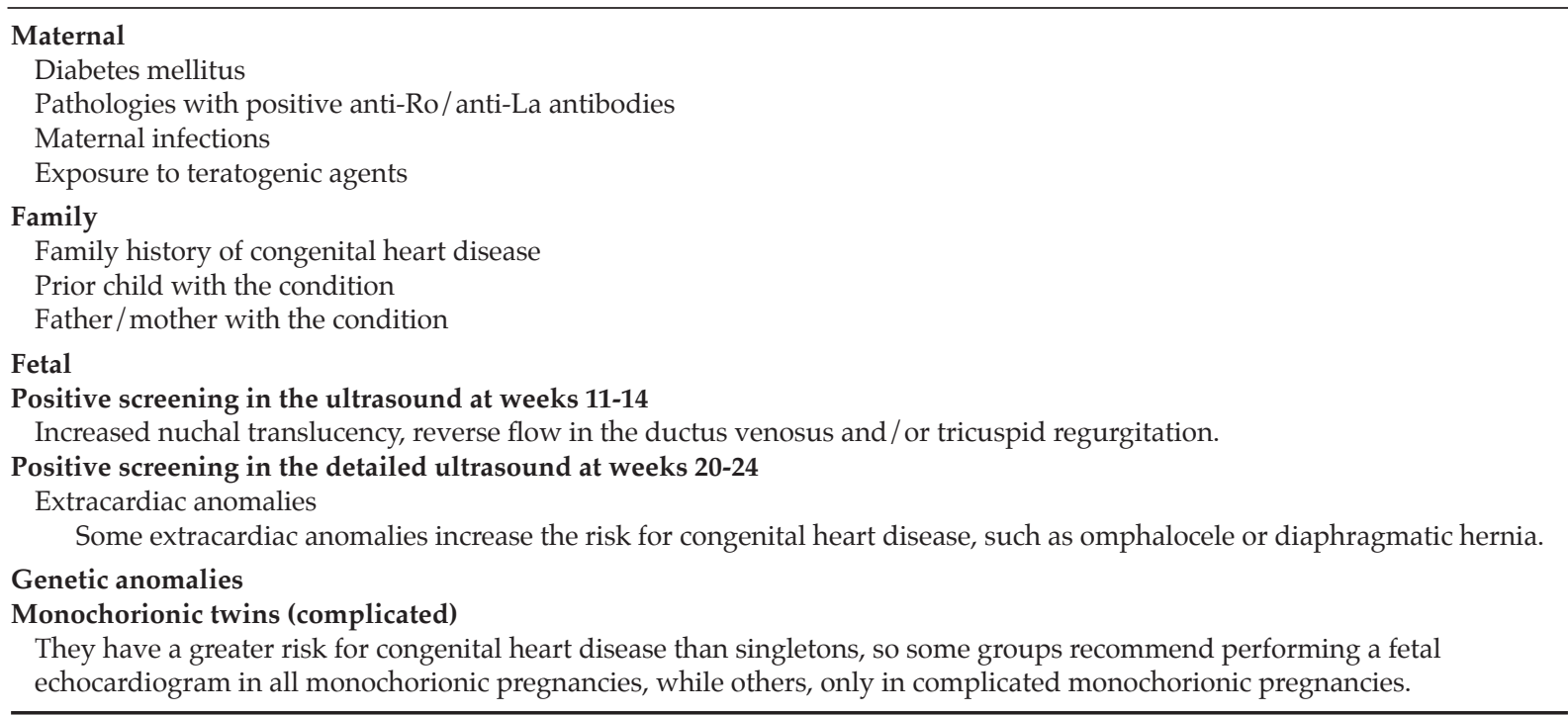


Is it possible to assess the fetal heart in the first trimester?

First trimester screening is done between weeks 11 and 14 of pregnancy, which started with the assessment of NT for the detection of trisomy 21 and other aneuploidies, and has extended for the diagnosis of several major malformations. ${ }^{19-26}$ An ultrasound at weeks 1114 may play an important role in the detection of $\mathrm{CHD}$ due to the direct visualization of the heart defect or the presence of ultrasound markers that might increase the risk.

\section{a. Direct visualization of congenital heart disease}

According to the ISUOG guidelines, at weeks 11-14, the heart assessment includes only recording a regular heart rate and the correct heart location in the left hemithorax (levocardia). ${ }^{27}$ Certain pathologies may be identified at this gestational age (Figure 4). Therefore, some authors recommend the early assessment of the fetal heart using the four-chamber and outflow tract views, which may be obtained after week 12 in most cases. ${ }^{19}$ Other views are, however, more difficult to obtain (Table 3). McAuliffe et al. reported that, at $13^{+5}$ weeks, the aortic and ductal arches could only be seen in $45 \%$ of cases and pulmonary veins, in $16 \%$ of studied fetuses. ${ }^{22}$

Lastly, it is worth considering that an "early fetal echocardiogram" has a high false negative rate and also a high false positive rate because, among other factors, certain heart structures may not be fully developed yet. ${ }^{19}$ Therefore, caution is required when providing counseling because a significant proportion of tests showing abnormal findings will finally result in a healthy heart.

\section{b. Risk markers of congenital heart disease in the first trimester}

The first-trimester ultrasound markers associated with CHD are increased NT, a pathological DV, and tricuspid regurgitation (Figure 5).

\section{Increased nuchal translucency}

The main ultrasound marker of risk for CHD in the ultrasound at 11-14 weeks is an increased NT. ${ }^{19}$ As observed in Figure 6, the risk for CHD increases as the NT increases. ${ }^{28}$ Sotiriadis et al. ${ }^{23}$ performed a systematic

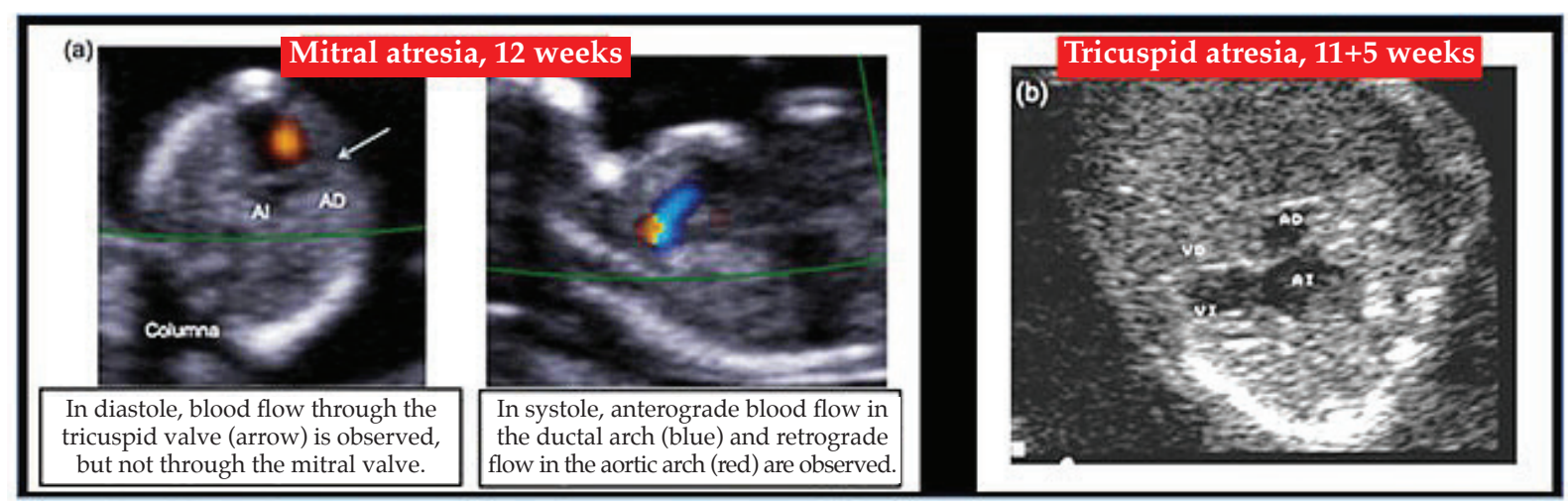

AI: left atrium; AD: right atrium; VI: left ventricle; VD: right ventricle; columna: spine.

TABLE 3. Visualization of the different fetal cardiac structures during the ultrasound at weeks 11-14

\begin{tabular}{lcccc}
\hline & $\mathbf{1 0}$ weeks & $\mathbf{1 1}$ weeks & $\mathbf{1 2}$ weeks & 13 weeks \\
\hline Four chambers & Yes & Yes & Yes & Yes \\
Outflow tracts & -- & -- & Yes & Yes \\
Three-vessel/three-vessel and trachea views & -- & -- & Yes & Yes \\
Aortic and ductal arches & -- & -- & Yes & Yes \\
Venae cavae & -- & -- & Yes & Yes \\
Pulmonary veins & -- & -- & -- & Yes \\
\hline
\end{tabular}

(Adapted from Hernández-Andrade E, Patwardhan M, Cruz-Lemini M, Luewan S. Early Evaluation of the Fetal Heart. Fetal Diagn Ther. 2017;42:161-173) 
review and a meta-analysis on the detection of CHD in fetuses with increased NT and normal karyotype; the results are shown in Table 4.

2. Pathological ductus venosus

Papatheodorou et al., ${ }^{24} \mathrm{did}$ a systematic review and a meta-analysis on the detection of CHD in fetuses with a pathological DV and normal karyotype; the results are shown in Table 5. On their side, Maiz et al., ${ }^{25}$ reported that the risk for CHD increased approximately 3 times if DV was abnormal, and reduced to the half if

FIGURE 5. Fetus of $12^{+6}$ weeks with (a) increased NT, (b) abnormal DV (reverse A wave [arrow]) and (c) tricuspid regurgitation (arrow)

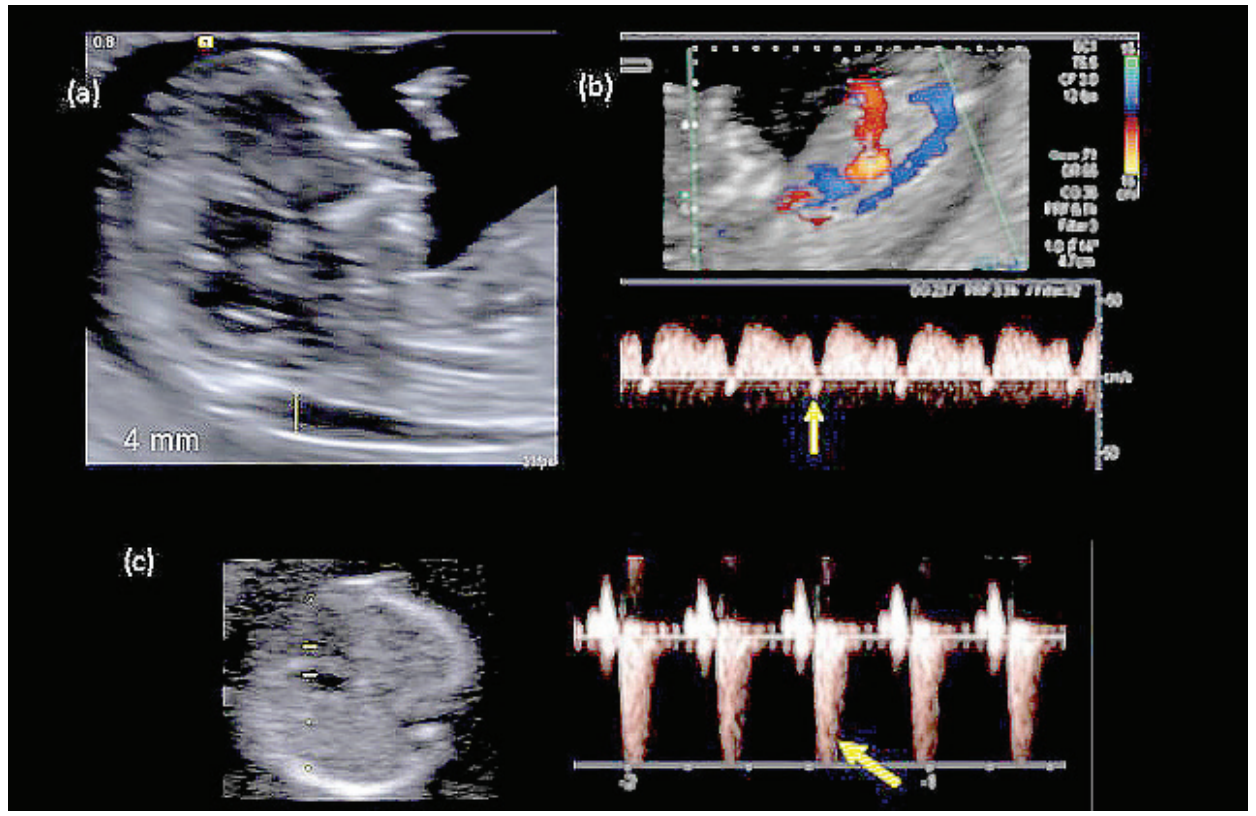

TABLE 4. Performance of increased nuchal translucency in the detection of congenital heart disease

\begin{tabular}{llc}
\hline NT greater than the $\mathbf{9 5}^{\text {th }}$ percentile & Sensitivity $(\%-95 \%$ CI) & $44.4(39.5-49.5)$ \\
& Specificity (\%-95\% CI) & $94.5(94.4-94.6)$ \\
& Positive likelihood ratio (LR+) (\%-95\% CI) & $8.22(4.70-14.38)$ \\
NT greater than the $\mathbf{9 9}^{\text {th }}$ percentile & Sensitivity (\%-95\% CI) & $19.5(15.9-23.5)$ \\
& Specificity (\%-95\% CI) & $99.1(99.1-99.2)$ \\
& Positive likelihood ratio (LR+) (\%-95\% CI) & $30.5(24.32-38.60)$
\end{tabular}

CI: confidence interval; NT: nuchal translucency; CHD: congenital heart disease (adapted from Sotiriadis A, Papatheodorou S, Eleftheriades M, Makrydimas G. Nuchal translucency and major congenital heart defects in fetuses with normal karyotype: a meta-analysis. Ultrasound Obstet Gynecol. 2013 Oct;42(4):383-9).

TABle 5. Performance of ductus venosus in the detection of congenital heart disease

\begin{tabular}{llr}
\hline Pathological DV, regardless of NT & Sensitivity $(\%-95 \%$ CI) & $50(0.27-0.73)$ \\
& Specificity $(\%-95 \%$ CI) & $93(0.88-0.96)$ \\
Pathological DV and increased NT & Sensitivity (\%-95\% CI) & $83(0.51-0.95)$ \\
& Specificity (\%-95\% CI) & $80(0.56-0.93)$ \\
Pathological DV and normal NT & Sensitivity (\%-95\% CI) & $19(0.12-0.29)$ \\
& Specificity (\%-95\% CI) & $96(0.92-0.98)$
\end{tabular}

CI: confidence interval; DV: ductus venosus; NT: nuchal translucency; CHD: congenital heart disease (adapted from Papatheodorou S, Evangelou E, Makrydimas G, Ioannidis J. First-trimester ductus venosus screening for cardiac defects: a metaanalysis. BJOG. 2011;118:1438-1445). 
it was normal (Figure 7).

3. Tricuspid regurgitation

Pereira et al., ${ }^{26}$ analyzed the contribution of tricuspid regurgitation at the time of diagnosis in the first trimester for CHD. Out of almost 41000 patients, tricuspid insufficiency was observed in $32.9 \%$ of fetuses with CHD and in $1.3 \%$ of fetuses without $\mathrm{CHD}$, and concluded that its use increased the diagnosis of CHD compared to the

FIGURE 6. Relation between NT and risk for CHD

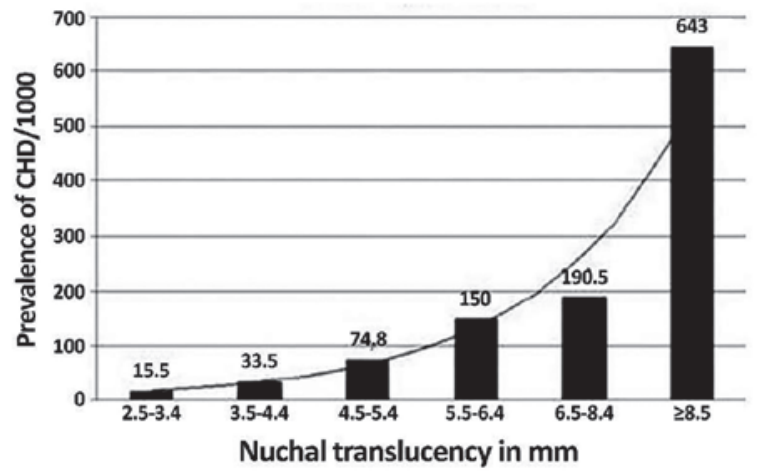

NT: nuchal translucency; CHD: congenital heart disease. Adapted from Clur SA, Bilardo CM. Early detection of fetal cardiac abnormalities: how effective is it and how should we manage these patients? Prenat Diagn. 2014; 34(13):1235-45. use of the NT alone. In addition, they reported that the rate of detection of $\mathrm{CHD}$, considering any of the 3 markers, was $57.6 \%$ (95\% CI: 4767.6) (Figure 8).

FIGURE 8. Prediction of congenital heart disease using $(A)$ NT and $(B) N T+D V+T V$

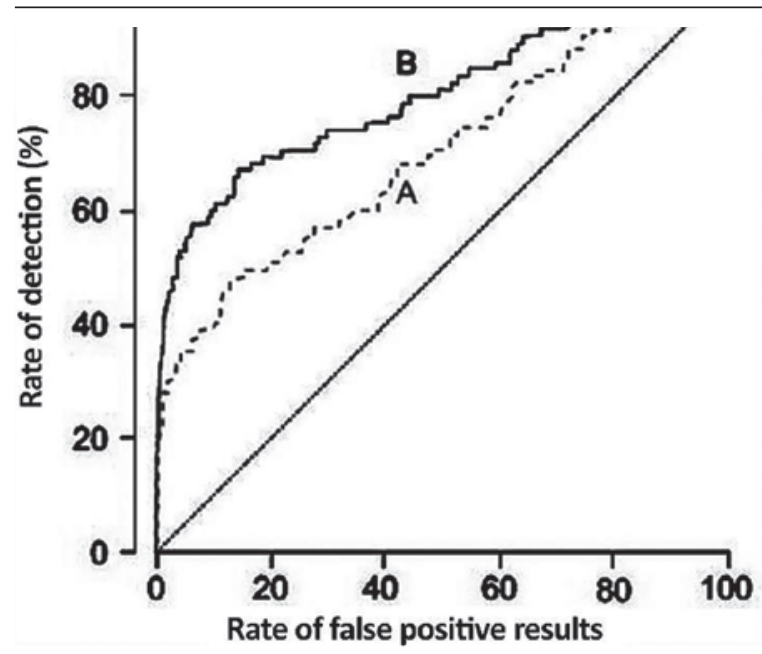

NT: nuchal translucency; DV: ductus venosus; TV: tricuspid valve.

Adapted from Pereira S, Gonopathy R, Syngeloki A, Maiz N, Nicolaides KH. Contribution of fetal tricuspid regurgitation in first-trimester screening for major cardiac defects. Obstet Gynecol. 2011 Jun; 117(6):1384-91.

FIGURE 7. Risk for CHD based on NT thickness and DV characteristics

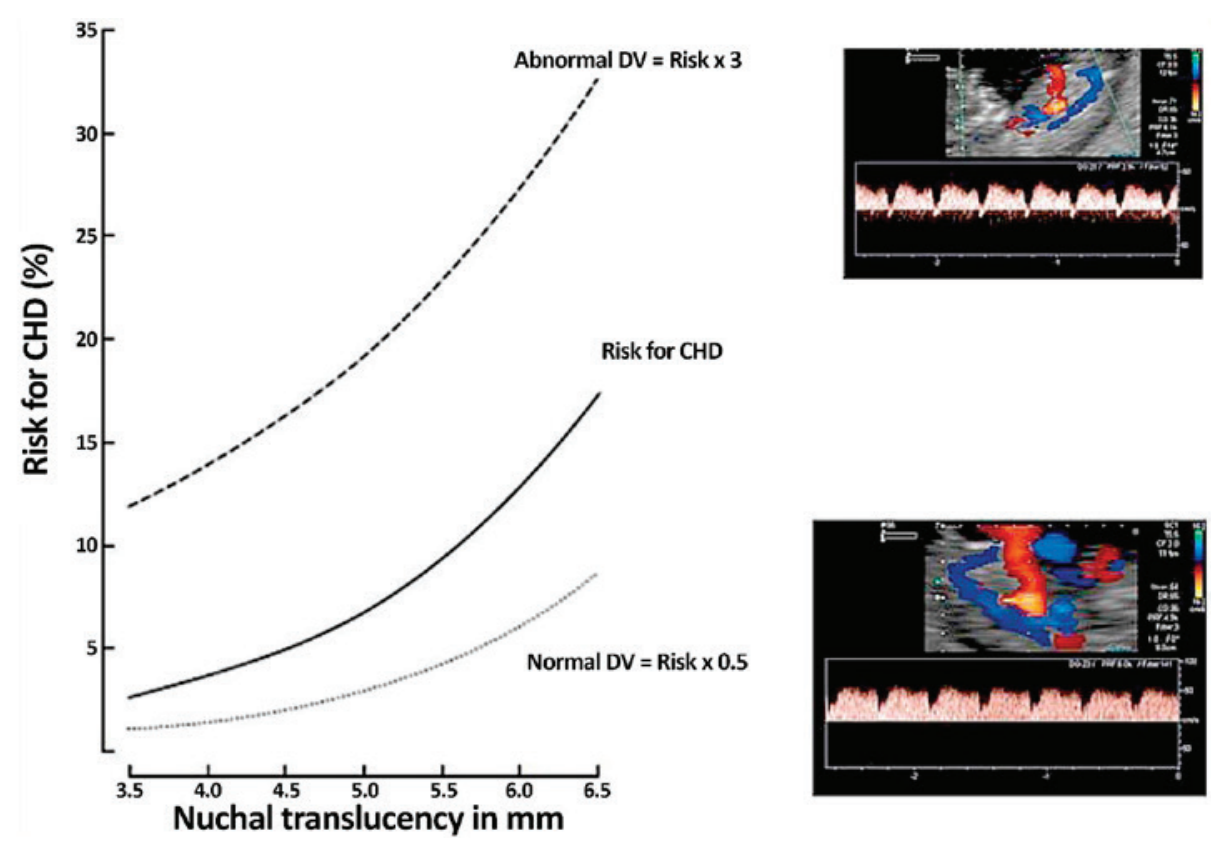

CHD: congenital heart disease; DV: ductus venosus; NT: nuchal translucency.

Adapted from Maix N, Plasencia W, Dogklis T, Faros E, Nicolaides K. Ductus venosus Doppler in fetuses with cardiac defects and increased nuchal translucency thickness. Ultrasound Obstet Gynecol 2008 Mar; 31(3): 256-60. 


\section{Management algorithm in case of prenatal} diagnosis of a congenital heart disease

If a CHD is suspected in the prenatal period, an attempt should be made to establish its characteristics and determine if it is isolated or associated with other condition, either other malformation and/or a genetic disorder. In this case, the steps to follow include a detailed fetal echocardiogram, a detailed morphological ultrasound, and a genetic assessment.

- Detailed fetal echocardiogram: It is performed by an expert in the prenatal diagnosis of heart disease for the purpose of establishing its characteristics. This test may include the assessment of the fetal thymus because a large number of fetuses with DiGeorge syndrome have thymic hypoplasia or thymus absence. Therefore, different methods for the prenatal assessment were proposed, including the thymic-thoracic ratio, ${ }^{29}$ which consists in assessing such ratio in a cross-sectional view of the chest, for the distance between the spine and the sternum and the distance between the aorta and the sternum (Figure 9). Results showed that the mean value was $0.44 \pm 0.04$ in normal fetuses and $0.25 \pm 0.09$ in fetuses with 22q11 deletion $(p<0.001)$. However, other groups questioned the usefulness of this ratio because the thymicthoracic ratio was smaller than in controls, not only in fetuses with 22q11 deletion, but also in those with conotruncal anomalies without 22q11 deletion, so they concluded that results should be interpreted with caution. ${ }^{30}$

- A detailed morphological ultrasound is done because approximately $25-45 \%$ of fetuses with CHD have associated extracardiac anomalies, especially atrioventricular canal, tetralogy of Fallot, and abnormal heart position.

- Genetic assessment: CHD behaves as a risk marker of genetic anomalies. Typical examples include atrioventricular canal and its strong association with trisomy 21 or conotruncal heart defects, which increase the risk for DiGeorge syndrome (22q11 deletion syndrome). Any genetic test that may be done requires invasive procedures, such as chorionic villus sampling or amniocentesis. Maternal risks, such as abdominal wall hematoma or infection, are very low. In relation to pregnancy loss, traditionally it was estimated that these procedures increased the risk by $1 \%$, but a recent systematic review ${ }^{31}$ showed that risks were smaller:

1. Amniocentesis: $0.11 \%$ (95 \% CI: -0.04-0.26).

2.Chorionic villus sampling: $0.22 \%$ (95\% CI: -0.71-1.16).

Once the specimen is obtained, the material may be assessed for chromosomal anomalies, microdeletion syndromes, and Mendelian disorders. The diagnostic performance will depend on the type of test available.

- Chromosomal testing: A standard

FIGURE 9. Thymic-thoracic ratio. Showing the measurement technique (on the left) and the difference in the thymic-thoracic ratio between 90 fetuses with heart disease and without 22q11 deletion and 20 fetuses with heart disease and 22q11 deletion

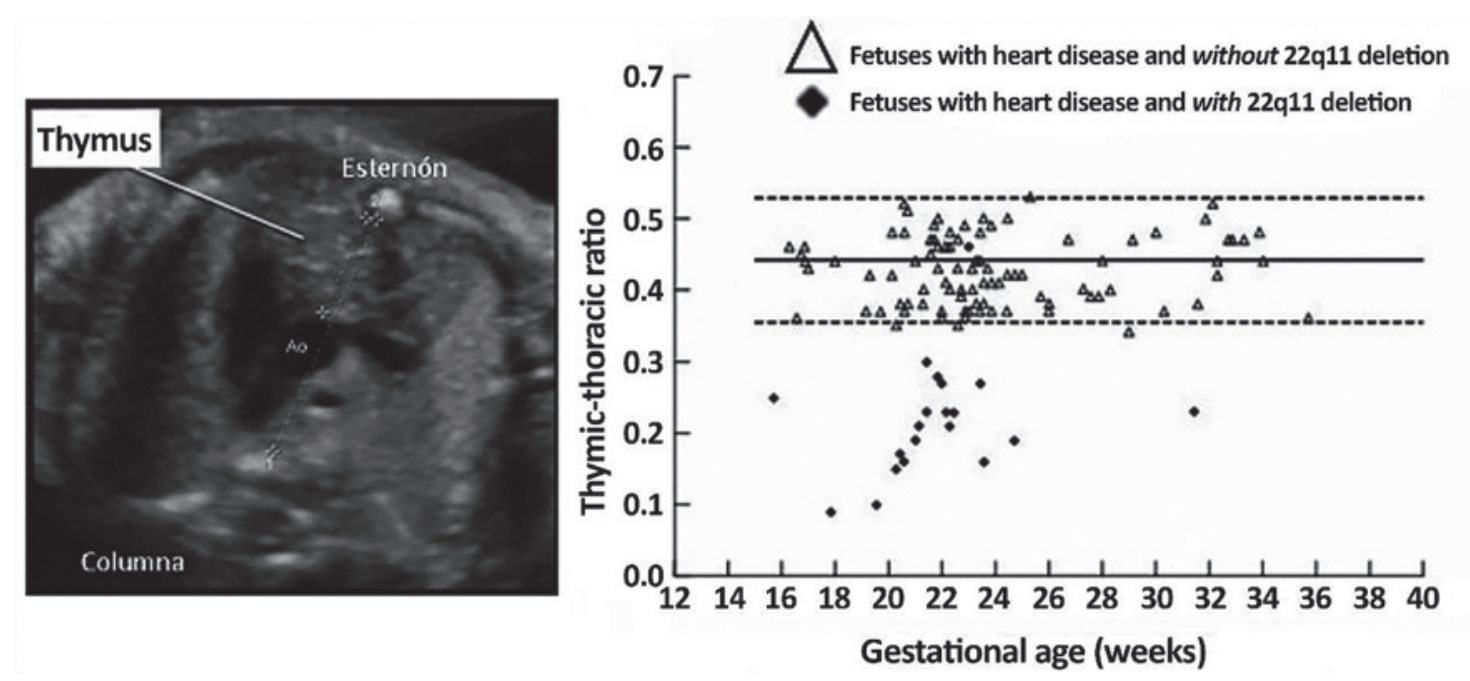

AO: aorta; esternón: sternum; columna: spine.

Adapted from Chaoui RI, Heling KS, Lopez AS, Thiel G, Karl K. The thymic-thoracic ratio in fetal heart defects: a simple way to identify fetuses at high risk for microdeletion 22q11. Ultrasound Obstet Gymecol. 2211 Apr; 37(4):397:403. 
karyotyping may detect numerical chromosomal abnormalities, such as trisomy 21, and structural chromosomal abnormalities, like unbalanced translocations. The frequency of chromosomal abnormalities will depend on the type of diagnosed CHD.

- Fluorescent in situ hybridization (FISH): This technique allows to determine the presence of aneuploidies and microdeletions/duplications, e.g., a 22q11 deletion in a conotruncal heart disease.

- Quantitative fluorescent polymerase chain reaction (QF-PCR): It allows to make a fast diagnosis (24-48 h) of the most common aneuploidies, such as trisomy 21, 18, 13, and sex chromosome anomalies.

- Chromosomal microarray analysis (CMA): A cytogenetic or chromosomal array (or microarray) is a molecular technique that allows to assess deletions or duplications in deoxyribonucleic acid (DNA) regions. Its resolution is 100 times higher than that of karyotyping, so it is useful to diagnose not only aneuploidies and large chromosomal abnormalities that can be detected with the traditional technique, but also other submicroscopic anomalies that are too small to be detected by karyotyping. ${ }^{24,25}$ Different studies have demonstrated that using microarrays in the presence of a CHD improved the detection of genetic anomalies between 7 and $12 \% .^{32-34}$ The limitation of this test is its high cost.

- Whole-genome sequencing or whole-exome sequencing: Although this test is still being investigated in the prenatal period, some pharmaceutical companies now offer it in certain clinical situations where a genetic anomaly is suspected after a negative array test.

\section{Obstetric follow-up}

Once the diagnostic evaluation is completed, which ideally characterized CHD, the next step is to establish if it is isolated or associated with other condition and the family receives counseling on the meaning of the different findings. The usual obstetric follow-up of maternal health should be provided (lab controls, blood pressure, etc.) together with the specialized follow-up of fetal health in order to reach a term pregnancy and prevent prematurity and its neonatal complications.
The type of delivery should be based on the obstetrician's judgment. In general, CHD is not a contraindication for a vaginal delivery. A newborn with a CHD should be delivered by a trained neonatal team at a neonatology unit capable of providing cardiovascular assessment and management.

\section{Fetal therapy in heart anomalies}

\section{a. Fetal cardiac interventions}

Prenatal interventions that are under investigation and should therefore not be considered a standard of care include valvuloplasty, stent placement, and pericardiocentesis. These procedures do not imply a significant risk for the mother, ${ }^{35}$ but for the fetus, with a fetal mortality rate of $11 \%$ as reported by the International Fetal Cardiac Intervention Registry (http:/ / www.ifcir.org).

Fetal critical aortic stenosis may lead to hypoplastic left heart syndrome (HLHS). ${ }^{36-39}$ The purpose of fetal aortic valvuloplasty is to unblock the ventricular outflow tract in order to improve ventricular function and allow left heart structures to develop (Figure 10). Fetal pulmonary valvuloplasty in critical pulmonary stenosis ${ }^{39,40}$ may potentially prevent progression to a single ventricle physiology due to severe hypoplasia of the right ventricle.

Severe oval foramen restriction ${ }^{41}$ in patients with HLHS leads to an increased pressure on the left atrium, with passive pulmonary vascular congestion and the development of lymphangiectasia and pulmonary vascular remodeling. These patients make up a sub-group with a high early neonatal mortality given that, at birth, they require an emergency balloon atrial septostomy (Rashkind intervention). Stent placement in the interatrial septum in the fetal period is feasible and may allow to reduce neonatal mortality and prevent the progression of the pulmonary vascular damage (Figure 11).

Severe pericardial effusion ${ }^{42}$ may lead to death due to cardiac tamponade. In some cases, serial pericardiocenteses (Figure 12) or a pericardioamniotic shunt placement are required.

\section{b. Therapy for arrhythmias}

These are uncommon but potentially severe.

\section{Fetal tachyarrhythmias}

Most are represented by reentrant supraventricular tachycardia and atrial flutter, and are diagnosed when the fetal heart rate is 
above 180-190 beats per minute. ${ }^{43-48}$ In general, the strategy with a greater chance for survival encompasses an attempt to reverse arrhythmia in utero; to this end, since this procedure may be very difficult, it is important to follow strict management protocols. The most commonly used antiarrhythmic agents include digoxin, flecainide, and sotalol and, to a lesser extent, amiodarone, and they may be used alone or in combination (especially in the case of fetuses with hydrops). A strict cardiac assessment and control of the mother is critical because all antiarrhythmic agents are potentially arrhythmogenic. The case of an intrauterine pacemaker placed in a fetus with refractory hydrops has been published recently, ${ }^{49}$ but this procedure is still in the early phases of investigation.

FIGURE 10. Aortic valvuloplasty in a fetus with critical aortic stenosis
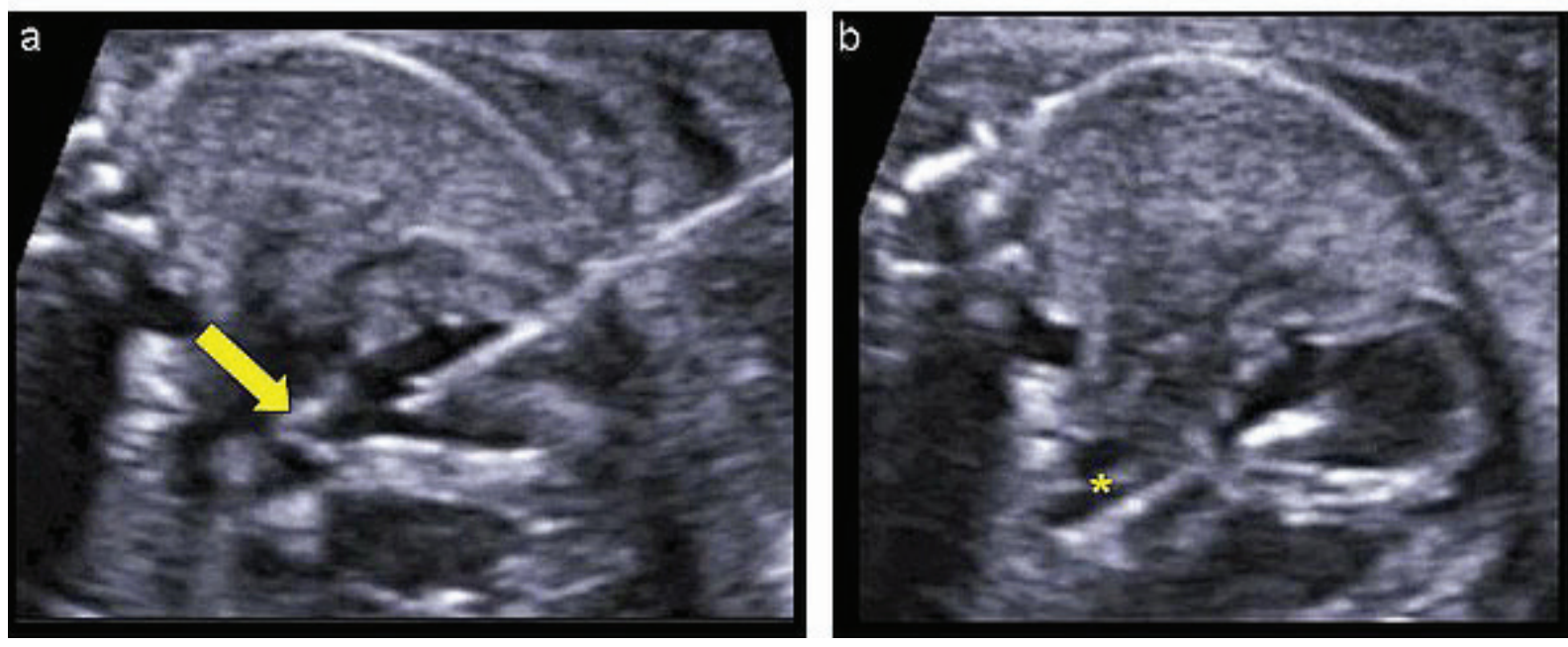

(a) Shows the needle inside the left ventricle facing the outflow tract (arrow). (b) Shows the guidewire $\left(^{*}\right)$ through the aortic valve, before inflating the valvuloplasty balloon.

Figure 11. Fetal septostomy with stent placement. Fourchamber view with stent placed in the interatrial septum

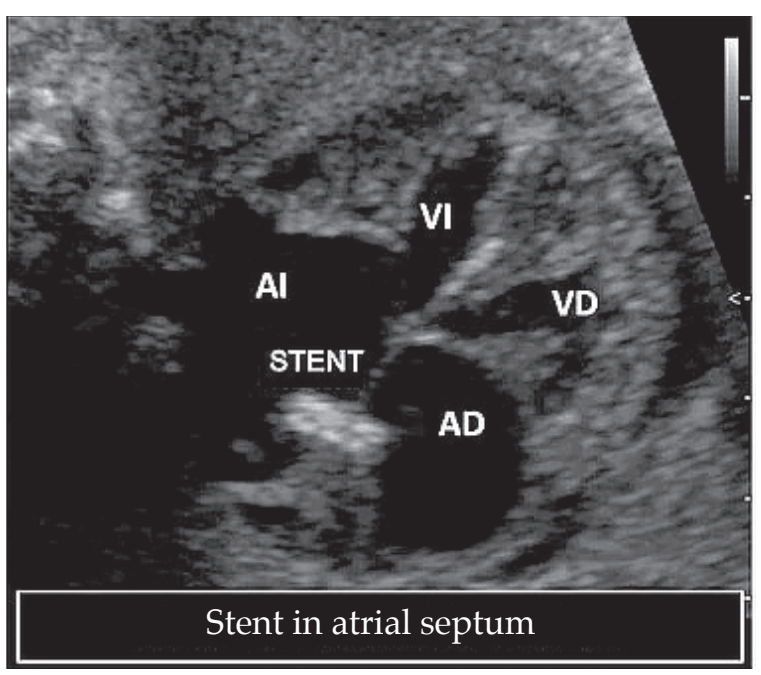

AD: right atrium; AI: left atrium

VI: left ventricle; VD: right ventricle.
FIGURE 12. Fetal pericardiocentesis in a fetus with a cardiac diverticulum, showing the needle (arrows) going into the pericardial cavity through the fetal thorax to drain a severe blood effusion

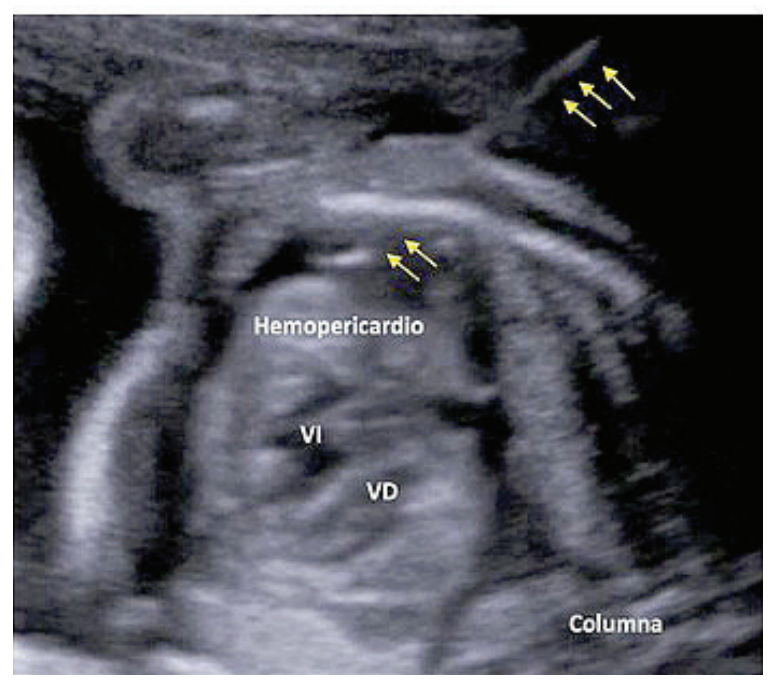

VI: left ventricle; VD: right ventricle; hemopericardio: hemopericardium; columna: spine. 


\section{Fetal bradyarrhythmias}

These are defined by a heart rate persistently below 100-110 beats per minute. Fetal bradyarrhythmias may occur in fetuses with structural heart disease or without an evident anomaly. In those without a structural heart disease, it is necessary to establish maternal levels of anti-Ro (anti-SSA) and anti-La (antiSSB) antibodies which, due to transplacental transfer, may result in conduction system damage and myocardial function involvement caused by the development of fibroelastosis, so the risk for complete atrioventricular block is $1-2 \%$ in those without family history and $15-20 \%$ in those with a prior affected child. ${ }^{10}$

Potential benefits have been described with the administration of corticosteroids to the mother, associated or not with sympathomimetic drugs, in case of prolonged mechanical PR interval (first- or second-degree block) or in the presence of fibroelastosis,,$^{50}$ but data are limited..$^{50}$

\section{FINAL COMMENT}

In spite of the importance of prenatal diagnosis of CHD, the rate of detection is still low in the general population. This reflects the limitations of prenatal diagnosis and warrants any effort made to improve knowledge in this area for the purpose of enhancing perinatal outcomes in children with CHD.

\section{REFERENCES}

1. Ailes EC, Gilboa SM, Riehle-Colarusso T, Johnson CY, et al. Prenatal diagnosis of nonsyndromic congenital heart defects. Prenat Diagn. 2014; 34(3):214-22.

2. Van Velzen CL, Clur SA, Rijlaarsdam ME, Bax CJ, et al. Prenatal detection of congenital heart disease--results of a national screening programme. BJOG. 2016;123(3):400-7.

3. Hautala J, Gissler M, Ritvanen A, Tekay A, et al. The implementation of a nationwide anomaly screening programme improves prenatal detection of major cardiac defects: an 11-year national population-based cohort study. BJOG. 2019; 126(7):864-73.

4. Ramaekers P, Mannaerts D, Jacquemyn Y. Re: Prenatal detection of congenital heart disease--results of a national screening programme. BJOG. 2015; 122(10):1420-1.

5. Van Velzen CL, Ket JCF, Van de Ven PM, Blom NA, et al. Systematic review and meta-analysis of the performance of second-trimester screening for prenatal detection of congenital heart defects. Int J Gynaecol Obstet. 2018; 140(2):137-45.

6. Marantz P, Grinenco S, Pestchanker F, Meller CH, et al. Prenatal diagnosis of CHDs: a simple ultrasound prediction model to estimate the probability of the need for neonatal cardiac invasive therapy. Cardiol Young. 2016; 26(2):347-53.

7. International Society of Ultrasound in Obstetrics and Gynecology, Carvalho JS, Allan LD, Chaoui R, Copel JA, et al. ISUOG Practice Guidelines (updated): sonographic screening examination of the fetal heart. Ultrasound Obstet Gynecol. 2013; 41(3):348-59.
8. Miller JL, De Veciana M, Turan S, Kush M, et al. Firsttrimester detection of fetal anomalies in pregestational diabetes using nuchal translucency, ductus venosus Doppler, and maternal glycosylated hemoglobin. Am J Obstet Gynecol. 2013; 208(5):385.e1-8.

9. Elmekkawi SF, Mansour GM, Elsafty MS, Hassanin AS, et al. Prediction of Fetal Hypertrophic Cardiomyopathy in Diabetic Pregnancies Compared with Postnatal Outcome. Clin Med Insights Womens Health. 2015; 8:39-43.

10. Panaitescu AM, Nicolaides K. Maternal autoimmune disorders and fetal defects. J Matern Fetal Neonatal Med. 2018; 31(13):1798-1806.

11. Mandelbrot L. Fetal varicella - diagnosis, management, and outcome. Prenat Diagn. 2012; 32(6):511-8.

12. Boucoiran I, Castillo E. No. 368-Rubella in pregnancy. J Obstet Gynaecol Can. 2018; 40(12):1646-56.

13. Prefumo F, Fichera A, Fratelli N, Sartori E. Fetal anemia: Diagnosis and management. Best Pract Res Clin Obstet Gynaecol. 2019. [Epub ahead of print].

14. Keighley CL, Skrzypek HJ, Wilson A, Bonning MA, et al. Infections in pregnancy. Med J Aust. 2019. [Epub ahead of print].

15. Drose JA. Scanning: Indications and Technique. In: Drose JA. Fetal Echocardiography. ${ }^{\text {nd }}$ ed. Missouri: Saunders; 2010. Págs.15-72.

16. Weston J, Bromley R, Jackson CF, Adab N, et al. Monotherapy treatment of epilepsy in pregnancy: congenital malformation outcomes in the child. Cochrane Database Syst Rev. 2016; 11:CD010224.

17. Hecher K, Gardiner HM, Diemert A, Bartmann P. Long-term outcomes for monochorionic twins after laser therapy in twin-to-twin transfusion syndrome. Lancet Child Adolesc Health. 2018; 2(7):525-35.

18. Salomon LJ, Alfirevic Z, Berghella V, Bilardo C, et al. Practice guidelines for performance of the routine midtrimester fetal ultrasound scan. Ultrasound Obstet Gynecol. 2011; 37(1):116-26.

19. Hernandez-Andrade E, Patwardhan M, Cruz-Lemini M, Luewan S. Early Evaluation of the Fetal Heart. Fetal Diagn Ther. 2017; 42:161-73.

20. Rossi AC, Prefumo F. Accuracy of ultrasonography at 11-14 weeks of gestation for detection of fetal structural anomalies: a systematic review. Obstet Gynecol. 2013; 122(6):1160-7.

21. Van Mieghem T, Hindryckx A, Van Calsteren K. Early fetal anatomy screening: who, what, when and why? Curr Opin Obstet Gynecol. 2015; 27(2):143-50.

22. McAuliffe FM, Trines J, Nield LE, Chitayat D, et al. Early fetal echocardiography-a reliable prenatal diagnosis tool. Am J Obstet Gynecol. 2005; 193(3 Pt 2):1253-9.

23. Sotiriadis A, Papatheodorou S, Eleftheriades M, Makrydimas G. Nuchal translucency and major congenital heart defects in fetuses with normal karyotype: a metaanalysis. Ultrasound Obstet Gynecol. 2013; 42(4):383-9.

24. Papatheodorou S, Evangelou E, Makrydimas G, Ioannidis J. First-trimester ductus venosus screening for cardiac defects: a meta-analysis. BJOG. 2011; 118(12):1438-45.

25. Maiz N, Plasencia W, Dagklis T, Faros E, et al. Ductus venosus Doppler in fetuses with cardiac defects and increased nuchal translucency thickness. Ultrasound Obstet Gynecol. 2008; 31(3):256-60.

26. Pereira S, Ganapathy R, Syngelaki A, Maiz N, et al. Contribution of fetal tricuspid regurgitation in firsttrimester screening for major cardiac defects. Obstet Gynecol. $2011 ; 117(6): 1384-91$.

27. Salomon LJ, Alfirevic Z, Bilardo CM, Chalouhi GE, et al. ISUOG practice guidelines: performance of first-trimester fetal ultrasound scan. Ultrasound Obstet Gynecol. 2013; 41(1):102-13. 
28. Clur SA, Bilardo CM. Early detection of fetal cardiac abnormalities: how effective is it and how should we manage these patients? Prenat Diagn. 2014;34(13):1235-45.

29. Chaoui R, Heling KS, Lopez AS, Thiel G, et al. The thymicthoracic ratio in fetal heart defects: a simple way to identify fetuses at high risk for microdeletion 22q11. Ultrasound Obstet Gynecol. 2011; 37(4):397-403.

30. Bataeva R, Bellsham-RevellH,ZidereV,AllanLD.Reliability of fetal thymus measurement in prediction of 22q11.2 deletion: a retrospective study using four-dimensional spatiotemporal image correlation volumes. Ultrasound Obstet Gynecol. 2013; 41(2):172-6.

31. Akolekar R, Beta J, Picciarelli G, Ogilvie C, et al. Procedurerelated risk of miscarriage following amniocentesis and chorionic villus sampling: a systematic review and metaanalysis. Ultrasound Obstet Gynecol. 2015; 45(1):16-26.

32. Hillman SC, McMullan DJ, Hall G, Togneri FS, et al. Use of prenatal chromosomal microarray: prospective cohort study and systematic review and meta-analysis. Ultrasound Obstet Gynecol. 2013; 41(6):610-20.

33. Committee on Genetics and the Society for MaternalFetal Medicine. Committee Opinion No.682: Microarrays and Next-Generation Sequencing Technology: The Use of Advanced Genetic Diagnostic Tools in Obstetrics and Gynecology. Obstet Gynecol. 2016; 128(6):e262-8.

34. Jansen FA, Blumenfeld YJ, Fisher A, Cobben JM, et al. Array comparative genomic hybridization and fetal congenital heart defects: a systematic review and meta-analysis. Ultrasound Obstet Gynecol. 2015; 45(1):27-35.

35. Wohlmuth C, Tulzer G, Arzt W, Gitter R, et al. Maternal aspects of fetal cardiac intervention. Ultrasound Obstet Gynecol. 2014; 44(5):532-7.

36. Marantz P, Aiello H, Grinenco S, Izbizky G, et al. Foetal aortic valvuloplasty: experience of five cases. Cardiol Young. 2013; 23(5):675-81.

37. Marantz P, Grinenco S. Fetal intervention for critical aortic stenosis: advances, research and postnatal follow-up. Curr Opin Cardiol. 2015; 30(1):89-94.

38. Friedman KG, Sleeper LA, Freud LR, Marshall AC, et al. Improved technical success, postnatal outcome and refined predictors of outcome for fetal aortic valvuloplasty. Ultrasound Obstet Gynecol. 2018; 52(2):212-20.
39. Otaño L, Meller CH, Aiello H. Avances en terapia fetal. Arch Argent Pediatr. 2013; 111(4):332-44.

40. Tworetzky W, McElhinney DB, Marx GR, Benson CB, etal.In utero valvuloplasty for pulmonary atresia with hypoplastic right ventricle: techniques and outcomes. Pediatrics. 2009; 124(3):e510-8.

41. Kalish BT, Tworetzky W, Benson CB, Wilkins-Haug L, et al. Technical challenges of atrial septal stent placement in fetuses with hypoplastic left heart syndrome and intact atrial septum. Catheter Cardiovasc Interv. 2014; 84(1):77-85.

42. McAuliffe FM, Hornberger LK, Johnson J, Chitayat D, et al. Cardiac diverticulum with pericardial effusion: report of two new cases treated by in-utero pericardiocentesis and a review of the literature. Ultrasound Obstet Gynecol. 2005; 25(4):401-4.

43. Hui L, Bianchi D. Prenatal pharmacotherapy for fetal anomalies: a 2011 update. Prenat Diagn. 2011;31(7):735-43.

44. Maeno Y, Hirose A, Kanbe T, Hori D. Fetal arrhythmia: prenatal diagnosis and perinatal management. J Obstet Gynaecol Res. 2009; 35(4):623-9.

45. Oudijk MA, Ruskamp JM, Ambachtsheer BE, Ververs TF, et al. Drug treatment of fetal tachycardias. Paediatr Drugs. 2002; 4(1):49-63

46. Jaeggi ET, Carvalho JS, De Groot E, Api O, et al. Comparison of transplacental treatment of fetal supraventricular tachyarrhythmias with digoxin, flecainide, and sotalol: results of a nonrandomized multicenter study. Circulation. 2011; 124(16):1747-54.

47. Shah A, Moon-Grady A, Bhogal N, Collins KK, et al. Effectiveness of sotalol as first-line therapy for fetal supraventricular tachyarrhythmias. Am J Cardiol. 2012; 109(11):1614-8.

48. Bravo-Valenzuela NJ, Rocha LA, Machado Nardozza LM, Araujo Júnior E. Fetal cardiac arrhythmias: Current evidence. Ann Pediatr Cardiol. 2018; 11(2):148-63.

49. Stirnemann J, Maltret A, Haydar A, Stos B, et al. Successful in utero transesophageal pacing for severe drug-resistant tachyarrhythmia. Am J Obstet Gynecol. 2018; 219(4):320-5.

50. Kan N, Silverman ED, Kingdom J, Dutil N, et al. Serial echocardiography for immune-mediated heart disease in the fetus: results of a risk-based prospective surveillance strategy. Prenat Diagn. 2017; 37(4):375-82. 